\title{
Advances in Mental Health
}

\section{Promoting and implementing family-focused interventions for families with parental mental illness: scoping and installation}

\section{Christine Mulligan, Mairead Furlong \& Sinéad McGilloway}

To cite this article: Christine Mulligan, Mairead Furlong \& Sinéad McGilloway (2019): Promoting and implementing family-focused interventions for families with parental mental illness: scoping and installation, Advances in Mental Health, DOI: 10.1080/18387357.2019.1614466

To link to this article: https://doi.org/10.1080/18387357.2019.1614466

曲 Published online: 16 May 2019.

Submit your article to this journal $\pi$

Џll Article views: 216

Q View related articles ¿

View Crossmark data \lceil 


\title{
Promoting and implementing family-focused interventions for families with parental mental illness: scoping and installation
}

\author{
Christine Mulligan (D), Mairead Furlong (i) and Sinéad McGilloway \\ Centre for Mental Health and Community Research, Department of Psychology, Maynooth University, \\ Maynooth, Ireland
}

\begin{abstract}
Objectives: This paper outlines the findings from the first stage of a research programme called PRIMERA (Promoting Research and Innovation in Mental hEalth seRvices for fAmilies and Children). This programme aims to identify, help implement and evaluate family-focused interventions for families where a parent has a mental illness, and promote a 'think family' service delivery agenda in the Republic of Ireland (Rol).

Methods: An initial scoping study was undertaken to: (1) assess the nature and extent of family-focused practice (FFP) in adult $(N=114)$ and child $(N=69)$ mental health services in the Rol; (2) review the international literature; and (3) undertake site/service visits to assess readiness for, and inform the implementation of, FFP.

Results: A national Expression of Interest (Eol) call led to 37 written submissions (20\% response rate) plus six further requests for involvement from interested community services. Fifteen sites/ services (35\%) were included in the research following critical appraisal and consultation. FFP across services/sites was smallscale or non-existent. Following a literature review and other strategic/resource considerations, all sites were invited to deliver the Family Talk (FT) intervention; 12 agreed to do so; three sites will deliver other programmes. A series of activities was undertaken by the research team to support early implementation. Discussion: This first phase of the research provides a critical starting point for promoting, and assessing the development of, FFP in mental health services in the Rol. Some useful generalisable lessons are also identified in terms of building capacity and beginning to change practice in this field.
\end{abstract}

\section{ARTICLE HISTORY}

Received 3 December 2018

Accepted 29 April 2019

\section{KEYWORDS}

Family-focused practice; family-focused intervention; parental mental illness; 'think family' approach; family mental health; familyfocused mental health practice

\section{Background}

Current experts in the field of mental health call for a family-focused or two-generational approach when treating an adult with a mental illness who is a parent. Family-focused practice (FFP) for families where a parent has a mental illness, commenced in the 1980s and is now part of several national initiatives in Australia, Finland and Norway (Falkov et al., 2016). FFP targets and supports the 'family unit' rather than just the individual receiving mental health support (Foster et al., 2016) and incorporates an interagency and strengths-based approach as well as some level of partnership between parents and mental health services. 
Unlike many other countries (e.g. UK, Sweden, Norway, Finland, Australia), there is a lack of national guidance and service awareness in the Republic of Ireland (RoI), on the need to support families where there is a parental mental illness (PMI) (Grant et al., 2018). While recent policy developments indicate a need for interagency collaboration to promote positive child outcomes (e.g. Better Outcomes, Brighter Futures, 2014), mental health services do not attend to the parental status of adult service users and typically, do not attempt to meet the needs of children in these families (Barnardos, 2014). Current mental health service provision is characterised by: (a) an individualised approach to assessment/treatment; (b) a lack of collaboration between Adult Mental Health Services (AMHS) and Child and Adolescent Mental Health Services (CAMHS); and (c) competency concerns amongst mental health professionals who may feel ill-equipped for undertaking familyfocused work (Barnardos, 2014). Furthermore, mental health services remain underresourced due to the recent economic recession in the RoI (and elsewhere). For example, the most recent figures indicate that in 2016, AMHS staffing in the community was at $76 \%$ of recommended levels, whilst CAMHS staffing was at $56 \%$ of optimal targets in the same year (HSE, 2016). Failures in mental health care are also frequently highlighted in the national media, particularly in relation to the provision of child mental health services.

A 'Think Family' approach has been adopted in Northern Ireland (NI) since 2009 (Donaghy, 2014, 2016) and whilst a recent evaluation indicated a high level of awareness of FFP among health and social care professionals, service provision was ad hoc and disjointed (Grant et al., 2018). A relatively recent study also compared FFP between two cohorts of registered psychiatric nurses in Ireland and Australia (Grant, 2014; Grant, Goodyear, Maybery, \& Reupert, 2016), as well as the impact of organisational and policy-related factors on these practices (Grant \& Reupert, 2016). A low level of FFP was reported, particularly among the Irish cohort, with only $15.6 \%$ trained in FFP. To date, no study has yet investigated the extent of FFP in adult and child mental health services within the Health Service Executive (HSE) (national health service) in the RoI.

For the first time in an Irish context, a research programme called 'PRIMERA' (Promoting Research and Innovation in Mental hEalth seRvices for fAmilies and children) (2017-2021) was established with the following two overarching aims: (1) to identify, help implement and evaluate family-focused interventions for families with PMI; and (2) inform a 'think family' care delivery agenda within mental health services in the RoI.

The current paper describes the initial exploratory phase of the PRIMERA research programme, during which we: (a) conducted a rapid review of the international literature; (b) undertook a national scoping study to identify and appraise the nature and extent of FFP within the HSE in the RoI; (c) conducted (ongoing) visits with selected services/sites to explore site readiness for the implementation of FFP nationally; and (d) supported the early implementation of family-focused interventions across the country.

\section{Method}

Firstly, a rapid review was undertaken during June-August 2017 to critically appraise the literature on the effectiveness of interventions for families with PMI. Several mainstream electronic databases (PubMed, PsychInfo, MEDLINE) were searched using terms such as 'parents with mental illness', 'parents with mental health issues/difficulties', 'family mental health', 'children of parents with mental illness' and 'family-focused mental health 
practice'. A snowball search strategy was also used to identify key systematic reviews and meta-analyses. Each included study was examined to identify those interventions with the strongest evidence of effectiveness. References of included studies were also perused (Greenhalgh \& Peacock, 2005) together with grey literature (e.g. government reports and pan-European research detailed on the Enter Mental Health website -http://www. entermentalhealth.net/) and expert overviews and policy documents (e.g. Beardslee, Solantaus, Morgan, Gladstone, \& Kowalenko, 2012; Social Care Institute for Excellence, 2011 'Think family' framework; and Australian COPMI (Children of Parents with Mental Illness) recovery frameworks).

Secondly, the scoping study involved administering, and collating the responses to, a national Expression of Interest (EoI) call issued by the, then National Director for Mental Health, during August-September 2017, to senior AMHS $(N=114)$ and CAMHS $(N=69)$ managers working in the HSE. This involved the use of a proforma which was prepared by the research team in consultation with the PRIMERA steering committee (PSC). Respondents were asked to respond to six open-ended questions requesting them to provide information on their services, including details on their existing/planned family-focused services for families with PMI (See Box 1). No quantitative data were collected. Submissions were then critically appraised on the basis of format and content of the programme, target population, and the scale of implementation (See Box 2), with follow-up phone-calls and emails undertaken as necessary. The scoping study was restricted to the HSE mental health services because: (a) the research is funded by the HSE Mental Health Division; and (b) a change in practice is considered most desirable and urgent within formal mental health services.

Thirdly, a series of follow-up site visits subsequently took place following a critical appraisal of all EoI submissions, to ascertain the extent to which services were willing and able to consider FFP implementation.

\footnotetext{
Box 1. Scoping questions in the expression of interest call.

(1) Demographic information

(2) Why are you interested in taking part in this research programme?

(3) Are any services in your area currently delivering any family-focused services/approaches or following any particular family-focused model?

(4) If 'yes, please name and describe these briefly below and then proceed to Question 6.If 'no'/'don't know', please proceed to Question 5.

(5) Do you know of any other similar family-focused services that are currently being implemented in other regions within Ireland?

(6) If 'yes', please name and describe these briefly below.
}

Box 2. Criteria for appraising proforma submissions.

- Does the intervention address parental mental illness and impact on family?

- What mental health difficulties are targeted in intervention?

- Which members of the family are targeted in intervention?

- Intervention content and format

- Interagency collaboration/delivery

- Recovery-oriented/service users involved in co-delivery

- Outcomes targeted in intervention

- Evidence base of intervention

- Site capacity to implement intervention.

- Willingness to engage in the research process 


\section{Findings}

\section{Rapid review}

A large number of effectiveness and policy papers were identified in the rapid review $(n=150)$. Six systematic reviews of intervention effectiveness were found, involving studies with sample sizes ranging from 13 to 57 (Bee et al., 2014; Fraser, James, Anderson, Lloyd, \& Judd, 2006; Huntsman, 2008; Reupert et al., 2013; Schrank, Moran, Borghi, \& Priebe, 2015; Siegenthaler, Munder, \& Egger, 2012). The interventions included in reviews, had been evaluated using randomised controlled trials (RCTs), non-controlled trials and qualitative studies, and fell into three main categories: (1) parent-based interventions (involving parent(s), occasionally with infants 0-2 years); (2) peer-support groups for children (7-18 years); and (3) family-based interventions involving both parents and children (5-18 years). We appraised and compared these interventions across several key domains (e.g. target population, content, and outcomes) (see Table 1).

The pooled results across reviews indicate positive outcomes overall, for children and parents, albeit based on heterogeneous interventions (e.g. Bee et al., 2014; Siegenthaler et al., 2012). However, there was relatively limited evidence for any single intervention. Our goal was to identify a family intervention which: (a) involved both children and parents; (b) targeted child, parent and family outcomes; (c) was suitable for different mental health diagnoses; $(d)$ targeted children across a wide age range; and (e) was replicable and capable of being implemented within services in the RoI. In this context, Family Talk (FT) emerged as an intervention with a potentially promising evidence base. This is a manualised, family-based (6-8 session) programme for which the evidence (based on several RCTs) indicates post-intervention increases in parent and child understanding of mental health, enhanced family functioning, improved mental health symptoms and greater resilience in both parents and children (e.g. Beardslee et al., 1992, 1997, 2003; Solantaus, Paavonen, Toikka, \& Punamäki, 2010). Further information on the FT programme and its benefits, is provided in Box 3. A multi-family group (MFG) programme, involving one RCT and longer-term follow-up, was also identified as having generated positive family outcomes (Compas et al., 2009, 2011), but with less evidence to support it.

\section{Assessing existing provision}

Following the EoI call, 37 submissions/responses were received from services across Ireland (October 2017) (20\% response rate), each of which was appraised according to the criteria in Box 2. Approximately 40\% (16/37) of submissions indicated existing, planned or previously implemented family-focused services to address PMI and its impact on children, whereas the remaining submissions included references to familyfocused services either for adults with mental illness $(9 / 37 ; 24 \%)$ or for children with mental health difficulties $(12 / 37 ; 32 \%)$.

Following further interrogation and follow-up of all submissions (e.g. by means of phone calls and emails with relevant contact persons), 9 sites were identified as potentially promising. These comprised of a mix of settings/services (community, inpatient) which were working with several target groups (parent, child and/or family) across a range of mental health diagnoses and different delivery formats (group, individual). These sites 
Table 1. Comparison of identified family-focused interventions across key domains.

\begin{tabular}{|c|c|c|c|}
\hline & Family-based interventions & Child peer support & Parent-based interventions \\
\hline Participants & Parents and children & Children & Parent(s), sometimes infants \\
\hline Age of child & $\begin{array}{l}\text { 5-18 years generally, one } \\
\text { intervention included children } \\
\text { aged } 4-7 \text { years }\end{array}$ & $7-18$ years & $\begin{array}{l}\text { Generally } 0-2 \text { years; a few } \\
\text { interventions with children } \\
\text { aged } 3-16 \text { years }\end{array}$ \\
\hline $\begin{array}{l}\text { Mental illness } \\
\quad(\mathrm{MI})\end{array}$ & $\begin{array}{l}\text { Parents have depression, anxiety, } \\
\text { bipolar, or substance abuse. } \\
\text { Less robust evidence for } \\
\text { schizophrenia /psychosis or } \\
\text { personality disorders. Generally, } \\
\text { children are not diagnosed with } \\
\text { a Ml. }\end{array}$ & $\begin{array}{l}\text { Children typically are not } \\
\text { diagnosed with a Ml. Their } \\
\text { parents typically have affective } \\
\text { disorders; a few studies } \\
\text { included parents with } \\
\text { psychosis. }\end{array}$ & $\begin{array}{l}\text { Parents generally have } \\
\text { depression, but may also } \\
\text { have anxiety, substance } \\
\text { abuse, personality disorders } \\
\text { and psychosis. Children are } \\
\text { not diagnosed with a Ml. }\end{array}$ \\
\hline $\begin{array}{l}\text { Format/ } \\
\text { setting }\end{array}$ & $\begin{array}{l}\text { Primarily community setting } \\
\text { individual and group-based } \\
\text { format. Occasionally inpatient } \\
\text { setting }\end{array}$ & $\begin{array}{l}\text { Community setting - group } \\
\text { based format }\end{array}$ & $\begin{array}{l}\text { Primarily community setting - } \\
\text { individual or group format. } \\
\text { Occasionally inpatient setting }\end{array}$ \\
\hline Components & $\begin{array}{l}\text { Varies among interventions. } \\
\text { Psychoeducation, family } \\
\text { communication, CBT, parenting } \\
\text { skills, crisis plans }\end{array}$ & $\begin{array}{l}\text { Psychoeducation and CBT for } \\
\text { child resiliency and peer } \\
\text { support }\end{array}$ & $\begin{array}{l}\text { Varies among interventions. } \\
\text { Psychotherapy for postnatal } \\
\text { depression, parent skills }\end{array}$ \\
\hline $\begin{array}{l}\text { Outcomes } \\
\text { assessed }\end{array}$ & $\begin{array}{l}\text { Child understanding and insight, } \\
\text { resiliency, child internalising } \\
\text { and externalising behaviours. } \\
\text { Parental mental health and } \\
\text { resiliency; family functioning } \\
\text { and communication }\end{array}$ & $\begin{array}{l}\text { Child understanding and insight, } \\
\text { child internalising and } \\
\text { externalising behaviours }\end{array}$ & $\begin{array}{l}\text { Generally maternal depression. } \\
\text { Occasionally parenting } \\
\text { behaviours. In a few } \\
\text { instances, child internalising } \\
\text { and externalising behaviours }\end{array}$ \\
\hline $\begin{array}{l}\text { Evidence base } \\
\text { summary }\end{array}$ & $\begin{array}{l}\text { Collectively, a good evidence- } \\
\text { base for improving child } \\
\text { outcomes. No single family- } \\
\text { based intervention has a very } \\
\text { robust evidence base. Family } \\
\text { Talk has most RCT evaluations } \\
\text { and may be a promising } \\
\text { intervention. }\end{array}$ & $\begin{array}{l}\text { Collectively, quite weak given the } \\
\text { number of uncontrolled } \\
\text { studies. However, one-off RCTs } \\
\text { of particular models indicate } \\
\text { positive short-term child } \\
\text { outcomes. }\end{array}$ & $\begin{array}{l}\text { Collectively, good evidence for } \\
\text { improving maternal } \\
\text { depression and parenting } \\
\text { behaviours. Little report on } \\
\text { child outcomes. However, } \\
\text { one-off RCTs of particular } \\
\text { models suggest some impact } \\
\text { on child outcomes. }\end{array}$ \\
\hline
\end{tabular}

were subsequently included in a series of 'fact-finding' site visits undertaken in JanuaryFebruary 2018, during which the research team met with key staff to clarify their service elements/approaches and ascertain their capacity and willingness to implement FFP within their service. The questions outlined in Box 2 were used to guide the discussions and the information obtained was entirely qualitative in nature, based on detailed notes taken by the research team. The 'results' showed that implementation was either non-existent (3 sites), in the planning stages (4 sites), or only small-scale (e.g. 5-10 families per year) (2 sites). For example, one site was planning to deliver systemic family therapy (SFT) whilst another was preparing to deliver a Multi-Family Group (MFG) programme. The latter has a strong evidence base in family mental health (McFarlane, 2016), although it is not specific to families with PMI. Systemic family therapy (SFT) is also underpinned by some evidence of effectiveness with regard to adults and children with a range of mental health problems (Carr, 2009, 2014).

There was a very high level of enthusiasm amongst all site personnel with regard to their willingness to be involved in a national study to promote and implement FFP. Most 'lead applicants' were social workers $(80 \%)$, followed by family therapists ( $8 \%)$, psychologists $(8 \%)$ and clinical nurse specialists (4\%). However, clinicians reported several challenges in their experience in delivering/proposing to deliver FFP including: (1) low managerial priority reflected in the poor collaboration between AMHS and CAMHS; 
(2) a lack of resources to deliver FFP; and (3) difficulties in identifying and engaging families.

\section{Adopting an evidence-based approach}

While the cross-site enthusiasm for FFP was encouraging, the under-developed and smallscale nature of existing provision presented a challenge for the research team in terms of the robustness of any subsequent evaluation and a collective desire to generate interest and momentum in FFP across Ireland. Therefore, it was decided by the research team, in consultation with the PSC, that resources could be used more strategically and effectively to identify, implement and evaluate one model that was evidence-based, replicable and capable of being implemented across several sites in Ireland. The information gathered from the rapid review and the site visits, suggested that FT was the most promising intervention for the reasons outlined earlier in in Box 3.

All 9 sites were subsequently invited to consider delivering this programme, 6 of whom agreed to do so in late March 2018. As outlined above, three sites were already planning their own interventions. Throughout 2018, word-of-mouth about Family Talk and the PRIMERA research spread, to the extent that six additional services/sites around the country contacted the research team and asked to be involved in the delivery and evaluation of FT (now 12 sites in total). These sites include HSE adult, child, and primary care mental health services, and several non-HSE organisations (e.g. Tusla (national Child and Family Agency), Saint John of God (Hospitaller Ministries), and Children and Young Persons' Services Committees). It was agreed by the PSC that non-HSE organisations could be involved in the research, in the interests of promoting inter-agency collaboration to support these families.

\section{Supporting installation and early implementation}

Initially, a small number of key staff (typically social workers) in each site had expressed an interest in delivering FT. However, given the lack of collaboration between AMHS and

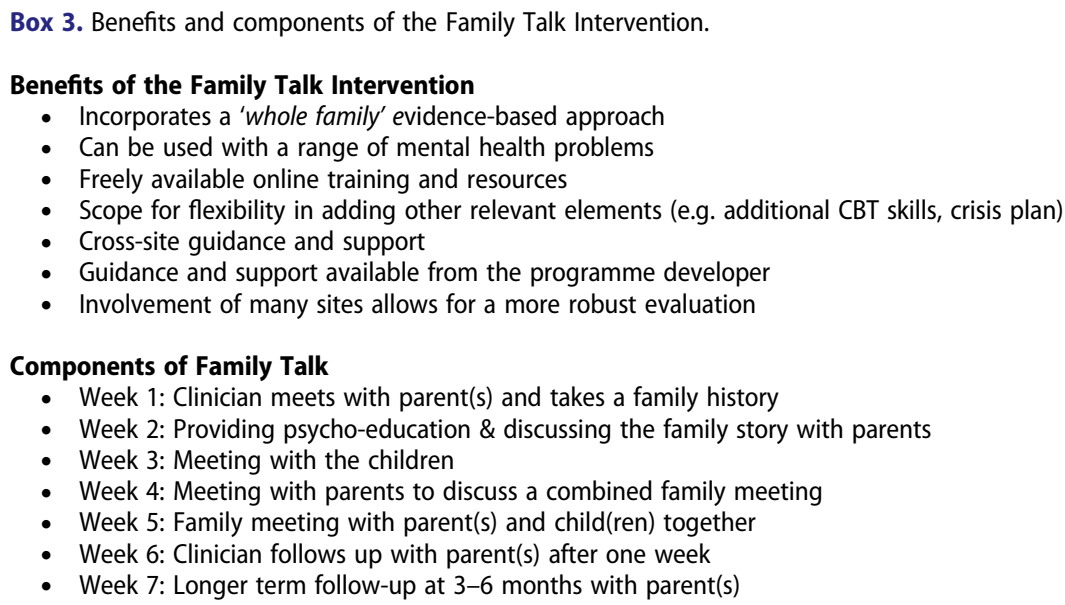

\section{Components of Family Talk}

- Week 1: Clinician meets with parent(s) and takes a family history

- Week 2: Providing psycho-education \& discussing the family story with parents

- Week 3: Meeting with the children

- Week 4: Meeting with parents to discuss a combined family meeting

- Week 5: Family meeting with parent(s) and child(ren) together

- Week 6: Clinician follows up with parent(s) after one week

- Week 7: Longer term follow-up at 3-6 months with parent(s) 
CAMHS in the RoI - and in order to secure the buy-in and support of management and colleagues - the research team was required (and requested) to 'make a case' to each multidisciplinary team (MDT) in each site according to their locus of care (e.g. adult in AMHS, children in CAMHS and Tusla) and to indicate the potential benefits of FT for their target population.

In adult services, we emphasised the benefits of FFP in helping to promote the recovery of the adult service-user. Therefore, supporting parents in their parenting role can help with their mental health, with additional benefits for the whole family who may, in turn, be involved in supporting the recovery of the parent (Falkov et al., 2016). We also emphasised the benefits of co-delivering FT with CAMHS/Tusla in terms of the experience of these organisations in working with families and children. With regard to sites where AMHS staff were already adopting a family-focused approach with some of their service users, we explained that FT complemented rather than duplicated their existing work because it specifically targets PMI and incorporates resources for working with both parents and children. Overall, the process of securing buy-in took approximately four months with considerable variation across sites. For example, the process of securing buy-in from CAMHS and Tusla was straightforward as they already believed, and understood, that supporting families with PMI can benefit a child's wellbeing in the short and longer term (Siegenthaler et al., 2012).

\section{Equipping staff teams for FT implementation}

We subsequently initiated and supported a series of activities in 2018 to facilitate early FT implementation across participating sites, as outlined below.

- Project leads in each site recruited staff to complete the FT e-learning training programme.

- Some sites organised awareness raising workshops.

- Regular peer supervision has been put in place to support FT delivery.

- The research team developed a complementary eLearning resource hub (www.cmhcr. eu/primera) to: (1) assist AMHS staff in working with children and families; (2) support CAMHS/Tusla staff in working with parents with mental health issues; and (3) provide guidance on other elements of implementation, such as how to recruit families to FT (Box 4). This was an important element in securing buy-in from participating sites.

- The research team - in consultation with site personnel - drafted FT information brochures and posters (as well as research pamphlets) for families and clinicians.

- The research team met, and liaised, with key site personnel to discuss talking to families about FT and the PRIMERA research, whilst also providing them with supporting documentation.

Importantly, the research team also organised and facilitated access to several free FFPrelated events in order to promote learning and collaboration among relevant stakeholders. In particular, we organised and hosted a day-long masterclass in September 2018 (with Dr Adrian Falkov), which was widely attended by our site personnel (clinicians and management), as well as other services interested in FFP, service users, funders, senior 
Box 4. eLearning Hub for PRIMERA Sites.

(1) Family Talk \& additions

(i) FT training manuals

(ii) Access to eLearning FT training

(iii) Examples of crisis care plans (recommended for inclusion)

(2) Training needs

(i) How to talk \& work with children

(ii) Psycho-education of mental health disorders

(iii) Explanation of recovery practices

(3) Recruitment considerations

(i) Engaging fathers

(ii) Identifying \& engaging families

HSE managers, national media, and researchers. The research team have also attended, and presented at, a number of local and national conferences and other related events (e.g. the Oireachtas Committee Meeting on the future of mental health; symposium in Belfast on 'Health and Social Care Professionals' Family Focused Practice with Parents who have Mental Illness, their Children and Families in Northern Ireland; and the Policy Forum for priorities in mental health in Ireland).

\section{Achieving buy-in to the research}

It was also necessary to secure buy-in to the research and evaluation of FT. Our proposed design - incorporating an RCT with an embedded process evaluation and economic appraisal - was discussed at length and agreed with stakeholders. The other three smaller interventions will be evaluated separately using a mix of questionnaires and interviews. Clinicians and managers in all participating sites understood the importance of producing robust evidence to persuade funders to recognise and support FFP and as a basis for developing national guidance in this area. The evaluation of FT will involve the identification and recruitment of approximately $80-100$ families who will be required to meet a number of inclusion criteria (see Box 5) and who will be assessed at baseline, 6and 12-month follow-ups along a number of dimensions, including child psychosocial functioning, family functioning, parental mental health, parent and child understanding of mental illness, parent and child resilience, and partner wellbeing.

\section{Raising public awareness}

In September 2018, the research team pitched the PRIMERA 'story' to the media (with the support of the university Communications Office) in order to raise public awareness of the need for FFP. We successfully attracted considerable media coverage from national radio, newspaper and social media platforms. Two national broadsheets (the Irish Examiner (6/09/2018) and The Irish Times (18/09/2018) carried articles on the research, with the latter producing a two-page feature. These were later circulated on social media platforms on Facebook, Twitter and relevant websites, with a potential readership of tens of thousands. The newspaper articles also generated interview requests from the national public service broadcaster (Raidió Teilifís Éireann (RTE)) on two (peak-time) programmes with over two million weekly listeners. The HSE communications office has also published an article in its regular staff magazine (available via e-zine to 100,000 HSE staff and 21,000 physical copies printed 4 times a year), whilst a recent article was 
Box 5. Family Talk Inclusion/Exclusion Criteria.

Inclusion criteria

(a) Parent (over 18 years) with a child(ren) aged 5-18 years, who is attending AMHS OR

(b) Parent(s) with a mental illness episode in the last 18 months and who had been under the care of a psychiatrist or MDT

OR

(c) Parent(s) currently attending a GP, psychologist, therapist or counsellor for mental health difficulties

\section{Exclusion criteria}

(a) Family/parent in crisis

(b) Active substance abuse/psychosis such that they cannot engage with intervention or research

(c) Parent in hospital

(d) Current acrimonious parental relationship (e.g. parental separation)

(e) Serious child protection issues

also published in the Hospital Professional News (HPN), a professional journal circulated to all hospitals (public and private) in Ireland (10-12 k physical copies and online version)). We are also currently working with the HSE Communications Office to raise awareness of the FFP work in each site by harnessing local media.

An outline of this phase of the research and a timeline of key milestones are shown in Figures 1 and 2 respectively.

\section{Discussion}

This initial exploratory phase of the research demonstrated that FFP in HSE mental health services in the RoI is extremely under-developed. While a response rate of 20\% (37/183 HSE sites) indicates some awareness of the importance of using FFP to support parents with mental illness, the subsequent appraisal of submissions revealed a very low level of service provision. These findings are similar to those reported by Grant et al. (2016) in which a low level of FFP was evident among an Irish cohort of registered psychiatric nurses when compared to an Australian sample. Given the lack of a policy framework in the RoI to support families where a parent has mental illness (Barnardos, 2014), it is perhaps unsurprising that overburdened mental health services place little priority on FFP for this population.

Nevertheless, this study showed that there was a significant appetite among clinicians to build capacity in FFP despite the challenges in so doing. Following a series of selected site visits and based on evidential, strategic and resource considerations, there was a considerable level of buy-in to both the FT intervention and to the evaluation. The use of an evidence-based and freely available intervention should help to reduce the time involved for sites in developing FFP, whilst avoiding the kind of duplication that can often occur within, often 'siloed', mental health services (MHR, 2012).

Furthermore, we know from implementation science that evidence-based interventions will not be effective if not properly implemented (Elliott \& Mihalic, 2004; Fixsen, Naoom, Blase, \& Friedman, 2005). Therefore, the research team invested considerable time and effort in ensuring that the factors required for successful implementation, were in place (insofar as possible) including: securing buy-in at local and higher management levels; developing a resource hub to assist implementation (e.g. guidance how to recruit and 


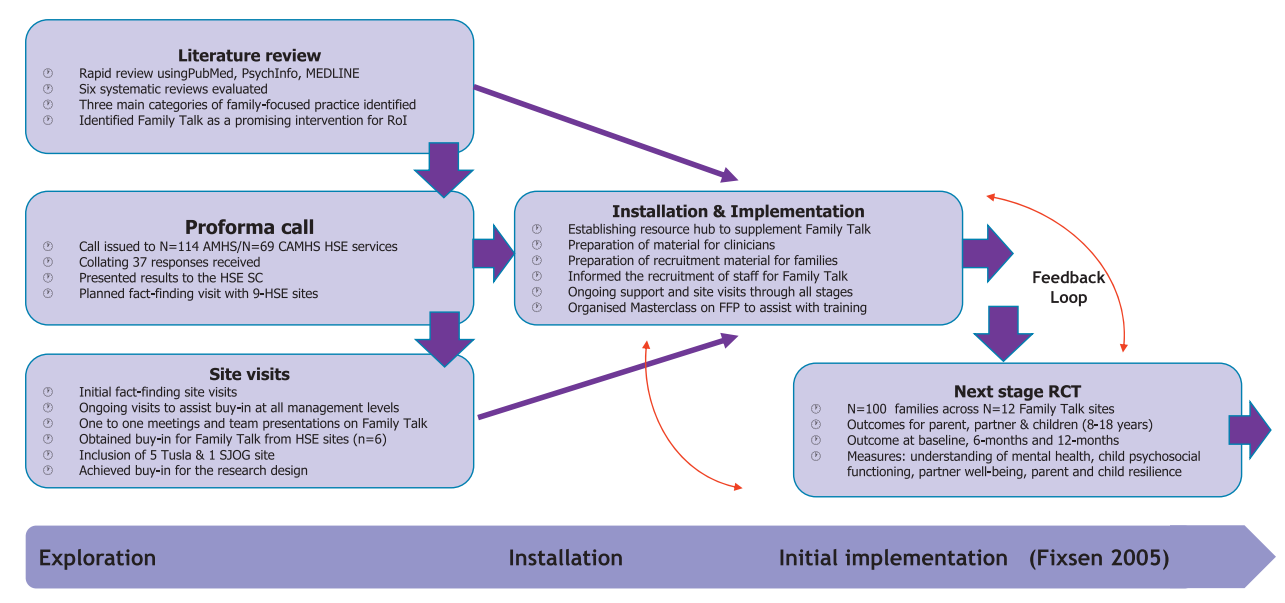

Figure 1. PRIMERA research programme: preparatory phase.

engage with families); helping sites to identify staff to deliver FT; raising awareness about referrals and cross-agency collaboration in delivering FT; producing recruitment materials; and utilising local and national media to raise public/service awareness about the need to support FFP. As noted by Fixsen et al. (2005), these kinds of 'implementation drivers' are essential for the successful introduction of new working practices. For example, identifying and supporting suitable clinicians is one of the key components in installing an evidence-based intervention within existing services. All of these activities should also help to promote a 'think family' care delivery agenda in the RoI. At the same time, however, the complexity and scale of the task that lies ahead should be acknowledged because it can often take years to effect a systems-wide change in practice (Falkov et al., 2016), and not least within the, often rigid and inflexible, structures of a national health system.

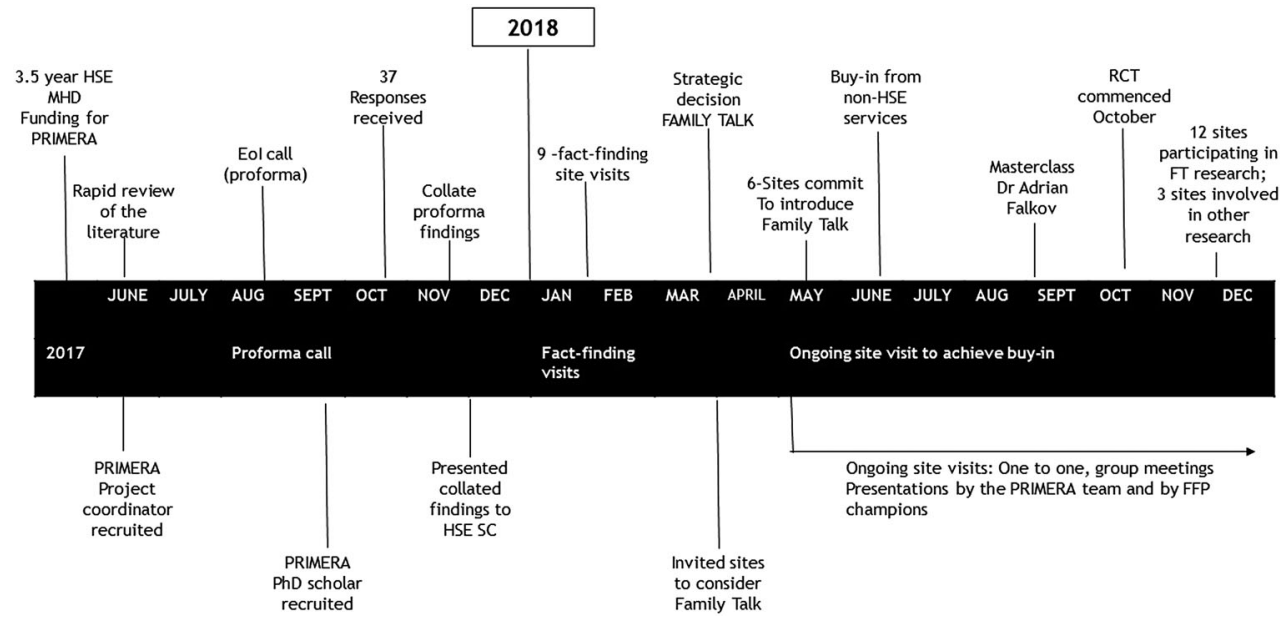

Figure 2. PRIMERA preparatory stage timeline. 
The overall aim of the PRIMERA research is to promote, implement and evaluate FFP in the RoI, with a specific emphasis on evaluating the implementation and clinical and cost-effectiveness of FT. A robust evidence base should help to persuade funders to support FFP and to develop a national framework for working with families affected by PMI. However, we are aware, based on the experience of other countries, that while an evidence base and a policy framework are important, they are not necessarily sufficient to change practice (Falkov et al., 2016). For instance, policy and legislative changes in the UK, Northern Ireland and Norway have increased service awareness of a 'think family' approach, but this has not necessarily translated into better 'on-the-ground' family-focused services (Grant et al., 2018; Lauritzen, Reedtz, Van Doesum, \& Martinussen, 2014). Once again, this highlights the many challenges of implementing and routinely embedding FFP within mental health services in the community.

For instance, 'Think Family' in NI joined with the larger UK Social Care Institute for Excellence (SCIE) initiative to inform an implementation plan to engage service users, review screening and assessment methodology and to develop an adult and child partnership protocol to assist cross agency work (Donaghy, 2014). A recent evaluation, conducted to assess the levels of FFP among health and social care professionals $(n=868)$ across all five NI Trusts, reported a good awareness of the Think Family initiative (Grant et al., 2018). However, despite the fact that one third of those surveyed, reported working with families impacted by parental illness on a daily basis ( $60 \%$ on a weekly or monthly basis), low levels of FFP were identified and service provision was somewhat disjointed (Grant et al., 2018).

Norway also introduced legislative changes in 2010 requiring the mandatory identification and assessment of children living in families where a parent is hospitalised with mental health difficulties and substance abuse. A recent report found that while identification of this 'hidden' population had increased, new practices were not yet consistent across all disciplines (Lauritzen et al., 2014). All of these indicate that the implementation of any new practice is a non-linear, recursive process which often requires considerable time (Fixsen et al., 2005).

Given these systemic difficulties, it is not surprising that the RoI lags behind international counterparts (Reupert \& Maybery, 2016). Australia, as world leaders, introduced FFP 25 years ago (Grant et al., 2018), while specialist service and professional training in mental health has also been introduced elsewhere (Beardslee, Solantaus, Morgan, Gladstone, \& Kowalenko, 2012; Lauritzen et al., 2014; Solantaus \& Toikka, 2006). For instance, the concept of a 'whole family' policy for PMI was introduced in the UK in 2007 (Evans \& Fowler, 2008).

Consequently, this research programme has adopted both a bottom-up and top-down approach to developing FFP in the RoI. The bottom-up element has involved investing in the early implementation of FFP and monitoring implementation throughout the lifetime of the research, whilst the top-down aspect has entailed assessing the evidence, liaising with decision makers/other key stakeholders and, in the future, informing and helping to develop national guidance/policies. Thus, the current development of FFP in the RoI has, uniquely, been very much research-led and informed, but undertaken in close collaboration with stakeholders at all levels. Experts in the field endorse the benefits of policymaker-researcher-service-provider collaborations in creating and sustaining change, although challenges remain (Nicholson et al., 2015). Recently, Falkov was quoted as saying that it typically takes at least five years of awarenessraising before practice 
changes, but that 'what is happening in the Republic [of Ireland is a much quicker move from awareness into action' (2018, Irish Times). Thus, the evaluation of FT (and the three other smaller interventions) is an important first step in building awareness and capacity in an attempt to ultimately change practice within the Irish mental health (and other) services in Ireland. However, much more will be needed. For example, complementary supports/activities could include child peer groups, working with parents alone (especially with regard to younger children), and raising service and public awareness of FFP.

\section{Strengths and limitations}

This is the first study to investigate existing FFP among statutory adult and child mental health services in the RoI. This began with a review of the evidencebase in order to inform the strategic decision to invite sites to implement Family Talk, thereby avoiding duplication and expediting delivery of FFP. Buy-in was successfully (and relatively quickly) secured within 12 sites across the RoI to deliver FT using a range of 'top-down' and 'bottom-up' levers (Nicholson et al., 2015), whilst we believe there is also merit in evaluating the work of the three other participating sites. In line with implementation science (Fixsen et al., 2005), considerable time and resources were invested by the research team in facilitating and supporting sites in the cross-agency implementation of FT. Lastly, FT will be evaluated using an RCT design with an embedded process evaluation and economic appraisal, all of which are relatively rare in this field (Bee et al., 2014).

However, the study was (necessarily) limited in its focus only on HSE AMHS and CAMHS services, thereby potentially excluding existing FFP within Tusla and the community and voluntary sector. While some Tusla and non-HSE sites later became involved in the study, this was more by accident than design. In addition, the rapid review lacks the rigour of a systematic review, but it was not possible within the study timeframe to conduct a more detailed review. Nonetheless, we have identified an evidence-based intervention (with the assistance of the programme designer, William Beardslee) that has proven to be attractive and intuitively appealing to the many stakeholders with whom we are working.

\section{Conclusion}

This research is the first of its kind in RoI to address the important issue of PMI and its impact on children and young people within HSE services. The scoping study showed a marked lack of FFP, but also, encouragingly, strong multi-site support and a desire amongst frontline and managerial staff to change the status quo. We successfully established a research-led collaboration - in the spirit of engaged research - with service providers, managers and policy makers to encourage, support and facilitate 15 sites across Ireland to implement cross-agency FFP, 12 of which will be involved in an evaluation of FT.

The staff and agencies across the 12 FT sites have agreed to: undertake the 10-hour online training; arrange additional MDT and peer-supervision meetings to support delivery; work through their existing waitlists to identify eligible families; liaise/work with other agencies; deliver the FT to eligible families; and to do this whilst already carrying heavy workloads. This amply demonstrates a clear recognition of the importance of this work and a strong commitment to tackle the needs of these vulnerable families in the RoI, 
despite the challenges that may lie ahead. With an estimated 30-40 clinicians now engaging in family-focused training, liaison and delivery, the work of building capacity has commenced. Our preparatory work provides a critical starting point and hopefully a strong basis for developing FFP in the RoI, while yielding key generalisable lessons to inform 'think family' research, practice and policy in Ireland and elsewhere.

\section{Acknowledgements}

We acknowledge with thanks, the funding provided by the Health Service Executive (HSE) and the support of the PSC, as well as all of the HSE, Tusla and St John of God's clinicians, managers and service users who have generously participated in the PRIMERA research programme to date.

\section{Disclosure statement}

No potential conflict of interest was reported by the authors.

\section{Funding}

This research is funded by the Health Service Executive Mental Health Division (2017-2021).

\section{ORCID}

Christine Mulligan (D) http://orcid.org/0000-0001-6362-4118

Mairead Furlong (iD http://orcid.org/0000-0002-9358-0635

Sinéad McGilloway (D) http://orcid.org/0000-0003-0988-3201

\section{References}

Barnardos. (2014). Patients. Parents. People. Towards integrated supports and services for families experiencing mental health difficulties. Dublin: Barnardos.

Beardslee, W. R., Gladstone, T. R. G., Wright, E. J., \& Cooper, A. B. (2003). A family-based approach to the prevention of depressive symptoms in children at risk: Evidence of parental and child change. Pediatrics, 112(2), e119-e131.

Beardslee, W. R., Hoke, L., Wheelock, I., Rothberg, P. C., van de Velde, P., \& Swatling, S. (1992). Initial findings on preventive intervention for families with parental affective disorders. American Journal of Psychiatry, 149(10), 1335-1340. doi:10.1176/ajp.149.10.1335

Beardslee, W. R., Salt, P., Versage, E. M., Gladstone, T. R. G., Wright, E. J., \& Rothberg, P. C. (1997). Sustained change in parents receiving preventive interventions for families with depression. American Journal of Psychiatry, 154(4), 510-515. doi:10.1176/ajp.154.4.510

Beardslee, W. R., Solantaus, T. S., Morgan, B. S., Gladstone, T. R., \& Kowalenko, N. M. (2012). Preventive interventions for children of parents with depression: International perspectives. Medical Journal of Australia, 196(7), 23.

Bee, P., Bower, P., Byford, S., Churchill, R., Calam, R., Stallard, P., ... Abel, K. (2014). The clinical effectiveness, cost-effectiveness and acceptability of community-based interventions aimed at improving or maintaining quality of life in children of parents with serious mental illness: A systematic review. Health Technology Assessment, 18(8), 1-250. doi:10.3310/hta18080

Better Outcomes, Brighter Futures. (2014). The national policy framework for children \& young people 2014 - 2020. Department of Children and Youth Affairs. Dublin, Ireland: The Stationery Office. 
Carr, A. (2009). The effectiveness of family therapy and systemic interventions for child-focused problems. Journal of Family Therapy, 31(1), 3-45. doi:10.1111/j.1467-6427.2008.00451.x

Carr, A. (2014). The evidence base for couple therapy, family therapy and systemic interventions for adult-focused problems. Journal of Family Therapy, 36(2), 158-194. doi:10.1111/1467-6427. 12033

Compas, B. E., Forehand, R., Keller, G., Champion, J. E., Rakow, A., Reeslund, K. L., ... Cole, D. A. (2009). Randomized controlled trial of a family cognitive-behavioral preventive intervention for children of depressed parents. Journal of Consulting and Clinical Psychology, 77(6), 1007-1020. doi:10.1037/a0016930

Compas, B. E., Forehand, R., Thigpen, J. C., Keller, G., Hardcastle, E. J., Cole, D. A., ... Colletti, C. (2011). Family group cognitive-behavioral preventive intervention for families of depressed parents: 18- and 24-month outcomes.. Journal of Consulting and Clinical Psychology, 79(4), 488-499.

Donaghy, M. (2014). Think family Northern Ireland. Barnardos Childlinks. (2), 19-25.

Donaghy, M. (2016). Think family, Northern Ireland in Diggins, M. Improving practice and working together across health and social care. In Parental mental health and child welfare work. Learning from success (Vol. 1, pp. 147-151). Hove: The Pavilion Annuals.

Elliott, D. S., \& Mihalic, S. (2004). Issues in disseminating and replicating effective prevention programs. Prevention Science, 5(1), 47-53. doi:10.1023/B:PREV.0000013981.28071.52

Evans, J., \& Fowler, R. (2008). Family Minded: Supporting children in families affected by mental illness. Essex, Ilford: Barnardo's.

Falkov, A., Goodyear, M., Hosman, C. M. H., Biebel, K., Skogøy, B. E., Kowalenko, N., ... Re, E. (2016). A systems approach to enhance global efforts to implement family-focused mental health interventions. Child \& Youth Services, 37(2), 175-193. doi:10.1080/0145935X.2016.1104104

Fixsen, D. L., Naoom, S. F., Blase, K. A., \& Friedman, R. M. (2005). Implementation research: A synthesis of the literature (Vol. FHI Publication \#231). Louise de la Parte Florida Mental Health Institute. Tampa, FL: National Implementation Research Network.

Foster, K., Maybery, D., Reupert, A., Gladstone, B., Grant, A., Ruud, T., ... Kowalenko, N. (2016). Family-focused practice in mental health care: An integrative review. Child \& Youth Services, 37 (2), 129-155. doi:10.1080/0145935X.2016.1104048

Fraser, C., James, E. L., Anderson, K., Lloyd, D., \& Judd, F. (2006). Intervention programs for children of parents with a mental illness: A critical review. International Journal of Mental Health Promotion, 8(1), 9-20. doi:10.1080/14623730.2006.9721897

Grant, A. (2014). Registered psychiatric nurses' practice with parents who have mental illness, their children and families, within general adult mental health services in Ireland. In $A$ thesis submitted in partial fulfilment of the requirements of Monash University for the degree of doctor of philosophy. Melbourne: Monash University.

Grant, A., Goodyear, M., Maybery, D., \& Reupert, A. (2016). Differences between Irish and Australian psychiatric nurses' family-focused practice in adult mental health services. Archives of Psychiatric Nursing, 30(2), 132-137. doi:10.1016/j.apnu.2015.07.005

Grant, A., Lagdon, S., Devaney, J., Davidson, G., Duffy, J. O. P., ... Monds-Watson, A. (2018). A study of health and social care professionals' family focused practice with parents who have mental illness, their children and families in Northern Ireland. Final report. Belfast: Queens University Belfast

Grant, A., \& Reupert, A. (2016). The impact of organizational factors and government policy on psychiatric nurses' family-focused practice with parents who have mental illness, their dependent children, and families in Ireland. Journal of Family Nursing, 22(2), 199-223. doi:10.1177/ 1074840716643770

Greenhalgh, T., \& Peacock, R. (2005). Effectiveness and efficiency of search methods in systematic reviews of complex evidence: Audit of primary sources. BMJ, 331(7524), 1064-1065. doi:10.1136/ bmj.38636.593461.68

HSE. (2016). Delivering specialist mental health services. Ireland. Retrieved from https://www.hse.ie/ eng/services/publications/mentalhealth/hse-mental-health-division-delivering-specialist-mental -health-services.pdf. 
Huntsman, L. (2008). Parents with mental health issues: Consequences for children and effectiveness of interventions designed to assist children and their families: Literature review: NSW Department of Community Services.

Lauritzen, C., Reedtz, C., Van Doesum, K. T., \& Martinussen, M. (2014). Implementing new routines in adult mental health care to identify and support children of mentally ill parents. $B M C$ Health Services Research, 14(1), 58. doi:10.1186/1472-6963-14-58

McFarlane, W. R. (2016). Family interventions for schizophrenia and the psychoses: A review. Family Process, 55(3), 460-482. doi:10.1111/famp.12235

Mental Health Reform. (2012). Promoting improved mental health services: Guiding a vision for change-manifesto. Dublin: Mental Health Reform.

Nicholson, J., Reupert, A., Grant, A., Lees, R., Maybery, D. J., Mordoch, E., ... Diggins, M. (2015). The policy context and change for families living with parental mental illness. In Parental psychiatric disorder: Distressed parents and their families (Vol. 3, pp. 354-364). Cambridge: Cambridge University Press.

Reupert, A. E., Cuff, R., Drost, L., Foster, K., van Doesum, K. T. M., \& van Santvoort, F. (2013). Intervention programs for children whose parents have a mental illness: A review. The Medical Journal of Australia, 199(3), 18-22. doi:10.5694/mjao11.11145

Reupert, A., \& Maybery, D. (2016). What do we know about families where parents have a mental illness? A systematic review. Child \& Youth Services, 37(2), 98-111. doi:10.1080/0145935X.2016. 1104037

Schrank, B., Moran, K., Borghi, C., \& Priebe, S. (2015). How to support patients with severe mental illness in their parenting role with children aged over 1 year? A systematic review of interventions. Social Psychiatry and Psychiatric Epidemiology, 50(12), 1765-1783. doi:10.1007/s00127015-1069-3

SCIE. (2011). Guide 30: Think child, think parent, think family: A guide to parental mental health and child welfare. London: Social Care Institute for Excellence.

Siegenthaler, E., Munder, T., \& Egger, M. (2012). Effect of preventive interventions in mentally ill parents on the mental health of the offspring: Systematic review and meta-analysis. Journal of the American Academy of Child and Adolescent Psychiatry, 51(1), e17-e18. doi:10.1016/j.jaac.2011.10.018

Solantaus, T., Paavonen, E. J., Toikka, S., \& Punamäki, R. L. (2010). Preventive interventions in families with parental depression: Children's psychosocial symptoms and prosocial behaviour. European Child \& Adolescent Psychiatry, 19(12), 883-892. doi:10.1007/s00787-010-0135-3

Solantaus, T., \& Toikka, S. (2006). The effective family programme: Preventative services for the children of mentally ill parents in Finland. International Journal of Mental Health Promotion, 8(3), 37-44. doi:10.1080/14623730.2006.9721744

Wayman, S. (2018, September, 18). My mummy didn't wake up this morning: When a parent has mental illness, who's looking out for the children? A new research project aims to help health services do a better job. The Irish Times, Health and Family Supplement, 8-9. 